https://helda.helsinki.fi

\title{
Misalignment as a Therapeutic Resource
}

\section{Voutilainen, Liisa}

2010-11-24

Voutilainen , L , Peräkylä , A \& Ruusuvuori , J E 2010 , ' Misalignment as a Therapeutic

Resource ', Qualitative Research in Psychology , vol. 7 , no. 4 , pp. 299-315 . https://doi.org/10.1080/147808809028

http://hdl.handle.net/10138/29483

https://doi.org/10.1080/14780880902846411

publishedVersion

Downloaded from Helda, University of Helsinki institutional repository.

This is an electronic reprint of the original article.

This reprint may differ from the original in pagination and typographic detail.

Please cite the original version. 
This article was downloaded by: [Voutilainen, Liisa]

On: 24 November 2010

Access details: Access Details: [subscription number 930114476]

Publisher Routledge

Informa Ltd Registered in England and Wales Registered Number: 1072954 Registered office: Mortimer House, 3741 Mortimer Street, London W1T 3JH, UK

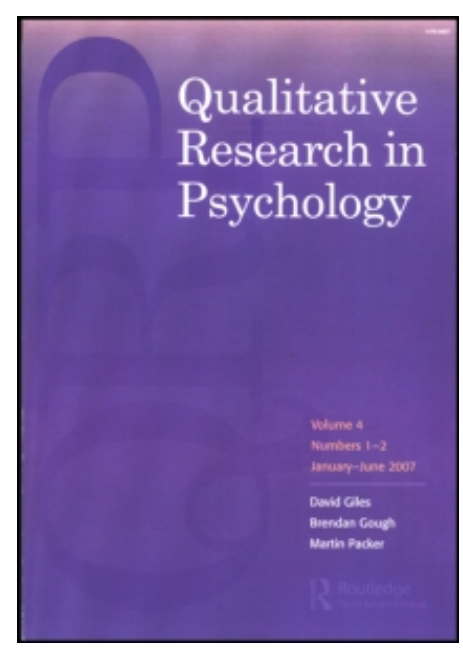

\section{Qualitative Research in Psychology}

Publication details, including instructions for authors and subscription information:

http://www.informaworld.com/smpp/title $\sim$ content=t781137235

\section{Misalignment as a Therapeutic Resource}

Liisa Voutilainen ${ }^{\mathrm{a}}$; Anssi Peräkyläa; Johanna Ruusuvuori ${ }^{\mathrm{b}}$

${ }^{\mathrm{a}}$ University of Helsinki, Helsinki, Finland ${ }^{\mathrm{b}}$ Finnish Institute of Occupational Health, Helsinki, Finland

Online publication date: 24 November 2010

To cite this Article Voutilainen, Liisa, Peräkylä, Anssi and Ruusuvuori, Johanna(2010) 'Misalignment as a Therapeutic Resource', Qualitative Research in Psychology, 7: 4, 299 - 315

To link to this Article: DOI: $10.1080 / 14780880902846411$

URL: http://dx.doi.org/10.1080/14780880902846411

\section{PLEASE SCROLL DOWN FOR ARTICLE}

Full terms and conditions of use: http://www.informaworld.com/terms-and-conditions-of-access.pdf

This article may be used for research, teaching and private study purposes. Any substantial or systematic reproduction, re-distribution, re-selling, loan or sub-licensing, systematic supply or distribution in any form to anyone is expressly forbidden.

The publisher does not give any warranty express or implied or make any representation that the contents will be complete or accurate or up to date. The accuracy of any instructions, formulae and drug doses should be independently verified with primary sources. The publisher shall not be liable for any loss, actions, claims, proceedings, demand or costs or damages whatsoever or howsoever caused arising directly or indirectly in connection with or arising out of the use of this material. 


\title{
Misalignment as a Therapeutic Resource
}

\author{
LIISA VOUTILAINEN, ${ }^{1}$ ANSSI PERÄKYLÄ,,${ }^{1}$ AND \\ JOHANNA RUUSUVUORI ${ }^{2}$ \\ ${ }^{1}$ University of Helsinki, Helsinki, Finland \\ ${ }^{2}$ Finnish Institute of Occupational Health, Helsinki, Finland
}

\begin{abstract}
The article reports conversation analysis of a single cognitive psychotherapy session in which an interactional misalignment between the therapist and the patient emerges, culminates, and is mitigated. Through this case study, the interactional practices leading to a rupture in therapeutic alliance and the practices leading to its mending are explored. In the session the therapist pursues investigative orientation in relation to the patient's experience under discussion, whereas the patient maintains orientation to "troubles-telling." The diverging projects of the participants amount to overt misalignment. Eventually, the therapist brings the relationship of the patient and herself as a topic of conversation in ways which turn the misalignment into a resource of therapeutic work. The microanalysis of actual interactional patterns in this single case is linked to discussions of therapeutic alliance in psychotherapeutic literature.
\end{abstract}

Keywords: alliance ruptures; cognitive psychotherapy; conversation analysis; emotion; misalignment

\section{Introduction}

A general aim in psychotherapy is to help patients recognise and reflect upon their emotions (see, e.g., Greenberg \& Safran 1987). Thus, when patients' emotional experiences are expressed and discussed in the sessions, the participants may be close to the core of the psychotherapeutic process. In clinical work, one key issue is how the therapist relates to the experience that the patient has described and expressed: whether or not the therapist should respond affectively to the patient's affective expressions, and how this responding should be done in order to retain and 'refresh' their therapeutic alliance (e.g., Horvath \& Symonds 1991; Martin, Garske \& Davis 2000; Safran \& Muran 2006).

A theory of interpersonal processes in cognitive therapy (Safran \& Segal 1990) suggests that the therapists should resist the patient's interpersonal pull, that is, not take the (affective) position that the patient invites (e.g., that of reassuring the patient) in case it would confirm the patient's dysfunctional representations (interpersonal schema) of interaction with others. In this article, we will analyse a single session of cognitive therapy in which the therapist does not take the position that the patient seems to be offering. In the first section of the session in focus, the therapist focuses on taking a distanced, external perspective to the patient's experience under discussion, whereas the patient talks about her negative emotion in an expressive manner and seems to invite affiliation from the therapist (cf. Ruusuvuori \& Voutilainen 2009). These diverging orientations lead to a clear

Correspondence: Liisa Voutilainen, University of Helsinki, Department of Social Research, Sociology, P.O. Box 18, 00014 University of Helsinki, Helsinki, Finland. E-mail: liisa.voutilainen@ helsinki.fi 
misalignment between the therapist and the patient that gets resolved in the course of the session.

What particularly interests us in this case is the skilful way in which the therapist manages to mitigate the misalignment and direct the discussion towards the prevalent therapeutic task of helping the patient to reflect upon her experience, in this case relations between her own emotions and how she interprets emotions of other people. Although the misalignment may have risen unintentionally, when it culminates the therapist brings the relationship of the patient and herself as a topic of conversation and thus manages to restore their common therapeutic goal and renew the therapeutic alliance (Martin et al. 2000). Thus, in the course of a therapy session the therapist turns a misalignment that threatens the therapeutic alliance into a therapeutic resource.

With the term misalignment we refer to the way in which participants to an interaction in a given moment steer their interaction in diverging directions. In a moment of misalignment, one party does not go along the direction that the other is proposing. Sometimes the direction that one party makes an effort to realize is persistent over a number of utterances; following Schegloff (2006, pp. 244-9) such persistent effort to maintain a particular direction can be called an interactional project. In the session in focus, the therapist and the patient have divergent interactional projects, and misalignment ensues. For us, interactional misalignment seems to be a key aspect of what in psychotherapeutic literature is called 'ruptures of the therapeutic alliance' (Safran \& Muran 2006).

The method of the study is conversation analysis (Schegloff 2006) as applied to the study of institutional interaction (Drew \& Heritage 1992; Arminen 2005). The method provides a way to explicate practices of interaction that the participants employ in reaching the goals of or in the encounter that is investigated. The key idea of the method is to observe the ongoing conversation as the participants themselves would see it: as a trajectory of interaction that evolves moment-by-moment, through the (spoken) activities of the participants. Thus, it is important to analyze, for instance, what sort of features in the therapist's turns would guide the patient to respond in a particular way, and vice versa.

Previous conversation analytic studies on therapy interaction have explicated practices through which the therapists manage the therapeutic tasks, for example, how formulations of the client's prior talk are used for different therapeutic purposes (e.g., Antaki 2008; Antaki et al. 2005; Buttny 1996; Davis 1986; Hutchby 2005; Peräkylä 2004; Vehviläinen 2003). Typically, conversation analytic studies use as data collections of short segments of interaction, which are collected from a number of sessions and which represent a particular recurrent phenomenon (such as formulations in the service of history-taking, see Antaki 2008). The present study is different: we do not describe a distinct practice but focus on a single session as a whole (cf. Leudar et al. 2008) in order to describe a process in which interactional projects (Schegloff 2006, pp. 244-9) of the participants misalign and the therapist deals with this misalignment. Safran et al. (2001) suggest that 'the process of recognizing and addressing weakness or ruptures in the therapeutic alliance may play an important role in successful therapy.' In terms of clinical work, this case study shows on a micro-interactional level what sort of combinations of turns of talk amount to a rupture and how a rupture can be dealt with.

\section{The Session in Focus}

Our data come from cognitive therapy with constructivist emphasis. This therapy approach, when compared to traditional cognitive therapy (Beck 1976), focuses more prominently on examining subjective meanings, emotions, and the therapeutic relationship (see Guidano 
1991; Safran \& Segal 1990; Toskala \& Hartikainen 2006). The session in focus is from a data corpus that covers 18 months of an individual therapy process that lasted two years. The patient has been suffering from depression, and the session is from the beginning of the second year of the therapy. Informed consent was obtained from the patient and the therapist. Any identifying information about the participants has been changed in the text and data extracts. In the original data the participants speak Finnish, and the extracts have been translated into English by the authors.

In the preceding session the participants have discussed about the possibility of the patient attending a job interview as well as a seminar despite the anxiety that these events cast in her. This is also the theme that the patient brings up at the beginning of the present session. Roughly three topics are talked about in the session: the patient's general feeling of anxiety, her decision to miss the job interview, and later the negative emotion in the current interaction between the participants. The first part of the session can be characterized as a mismatch in terms of the participants' projects. During the first 20 minutes of the session, the therapist positions herself and the patient as co-investigators of the patient's emotions, whereas the patient seeks to position herself as a troubles-teller (Jefferson 1988) and the therapist as an affiliating recipient of the trouble. Affiliation is a response that troubles-telling makes relevant in everyday talk: taking up the problematic experience that the co-participant has disclosed and showing recognition of it. Besides everyday talk (ibid), this kind of response has been reported also from clinical encounters, including cognitiveconstructivist psychotherapy (Ruusuvuori 2005, 2007; Ruusuvuori \& Voutilainen 2009) In this particular session, however, the therapist does not respond this way. The mismatch in the session in focus can be seen as between the therapist's orientation to the therapeutic task at hand (in this particular session) and the patient's orientation to general (everyday) practises of conversation.

In the latter part of the session, the problems in the interaction between the participants become attended to as a topic of talk, as the therapist brings up the patient's possible feelings towards the therapist. The therapist then also starts to show affiliation. This way the therapist transforms her project, and at the second part of the session the participants end up in more complementary positions exploring their relationship. However, in the details of the interaction, both the participants also retain their diverging projects. The patient maintains the frame of troubles-telling, describing her anxiety, while the affiliation that the therapist offers takes place as it were within the therapist's reflective, investigative project rather than the troubles-telling frame of the client. The therapist makes efforts to engage the patient in co-investigation of the emotion, and her success in this effort varies moment by moment. In what follows we will describe the participants' projects and their shifting (mis)alignment. Our main focus is on the therapist's work.

\section{First Phase of the Session: Distancing from the Emotion}

In the first 20 minutes of the session, following the patient's descriptions of problematic experience, the therapist avoids affiliating with the patient's troubles-telling and instead suggests a rational or fact-oriented line of conversation to be followed. In this first "phase" of the session, the therapist's responses to the patient's disclosures can be characterized as follows: she does not acknowledge the patient's preceding turn in any way but makes a follow-up question or a request of confirmation that is initiative rather than responsive: with her utterance she takes up an aspect of the topic that differs from the one that the patient has centred on in her preceding turn of talk. We have located three types of such distancing turns of talk in this phase of the session. 


\section{Focusing Away from Emotion}

In some of her turns that follow the patient's emotional disclosure, the therapist shifts the focus of the talk away from the emotional experience (anxiety) that the patient foregrounds in her preceding utterance. Such a shift takes place in extract 1 below. The extract shows the patient's disclosure and the therapist's response just in the beginning of the session. In lines 10-13 the patient refers to a job interview and to a seminar, which have been discussed in the previous therapy session. The therapist's opening question about things moving further in line 2 can also be heard as to refer to these issues from the previous session (for key to transcription symbols, see appendix).

\section{Extract 1}

1 (.)

2 T: So(.)\#how have\# .hhh the (.) things(h)[now,

3 P: $\quad[(($ Sighing $))$

4 (.) \#£well£\#[eh (.). snff

5 T: $\quad$ [moved furtherf,

6 P: @Well I: do:n't know @I've been agonizing $(0.5)$ and

$7 \quad$ \#anxi- ous $<$ now\# (1.0) \#all the time(h)\#

8 T: \#Tell me more\# .hff

$9 \quad(0.4)$

10 P: Well hhh @I don't know@ everything (.) makes me stressed

11 \#I: already\# made up my mind that I wo:n't \#go\# to

12 the job interview \#and\# (1.2) \#and then\# hhh (0.5) @ the

13 seminar makes me stressed and@,

$14 \mathrm{~T}$ : So you went to see the place?

15 P: Mm yeah,

In lines 4, 6-7, and 10-13, the patient responds to the therapist's opening question (lines 2 and 5) describing a strong negative experience. She uses intensive affect words agonizing and anxious and an extreme case formulation all the time (on extreme case formulations, see Pomerantz 1984; Edwards 2000). In line 8 the therapist treats the patient's turn as a gloss that is to be opened (see Jefferson 1988) as she responds by a particle ('Noh' in the original Finnish data) that invites specification and in this context can be freely translated as 'tell me more.' At this point the therapist treats the patient's disclosure in a manner that can be heard as (possibly) projecting affiliation with the patient's experience. However, this affiliation will not emerge as the interaction unfolds.

In lines 10-13 the patient elaborates her problematic experience: she gives another extreme-case formulation of it (everything makes me stressed) and then tells about her decision of not going to the job interview, and after a pause (line 12) states another distressing thing, the seminar. Sandwiched to the description of anxieties, the patient thus also offers news about her decision about the job interview that has been discussed in the previous session.

In line 14 the therapist receives the end part of the patient's utterance on being nervous about the seminar with a fact-oriented follow-up question ('So you went to see the place') about the patient's relation to the seminar that the patient has mentioned as one cause of her anxiety. The therapist receives the patient's account without acknowledging the patient's turn as a delivery of problematic news about her mental status and thus 
bypasses the emotional elements of the patient's utterance. She avoids taking up the position of an affiliating troubles recipient that the patient's utterance made relevant (in terms of everyday conversation) (cf. Jefferson 1988; Jefferson \& Lee 1992; Ruusuvuori 2005; Ruusuvuori \& Voutilainen 2009) as well as of somebody who would accept or evaluate the patient's decision about the job interview.

In the subsequent interaction, the participants maintain similar positions as above: the patient recurrently returns to describe her anxieties in an expressive manner, and the therapist shifts the focus away from the experience as such to fact-oriented investigation of the situations about which the patient is nervous. This indicates that the participants have diverging projects: with her expressive talk and resistance to investigative orientation, the patient positions herself as troubles-teller and invites affiliation from the therapist whereas the therapist repetitively pursues the investigative orientation.

\section{Detailing the Emotional Experience in a Detached Way}

Another type of distancing response involves that the therapist invites the patient to scrutinize her emotional experience. This entails that the therapist does address the patient's problematic experience but takes an external and detached position towards it. Extract 2 shows a topical shift where the therapist starts to focus on the anxiety that the patient has been expressing. The extract begins from the therapist's question concerning the patient's current feelings, following which the patient engages in troubles-telling.

\section{Extract 2}

1 T: .hff And now krh krhhm ((clears throat))

2 (0.5) you are somehow like wondering that why I am

3 this anxious and nervous now [.hhh

4 P: [Yeah,

$5 \quad(0.9)$

6 P: $\uparrow$ Yeah (0.8) \#somehow I have lately felt like

$7 \quad$ all the time \#.hhh \#mh\# hhh felt terribly (0.3) anxious

8 (.)\#constantly and that kind of bad feeling\# (1.4) like

9 physically and mentally he .hhh (2.0) awfully tired and,

10 (4.0)

$11 \mathrm{~T}$ : But is i- does this mean the- (0.7) \#mth\# anxiety then

12 that you are more anxious than depressed or like both and

13 both depressed and anxious [.hhh

$14 \mathrm{P}$ : [.hhh hfff Well I guess more anxious,

$15 \quad(1.2)$

16 T: \#But you have been more like depressed earlier

17 [haven't you\#,

18 P: [Yeah (0.7) yeah (.) well both and,

19 (0.3)

$20 \mathrm{~T}: \mathrm{Mh}$,

$21 \mathrm{P}:$ hff

22 (2.8)

$23 \mathrm{P}$ : But that \#kind of\# .hhh \#mmm\# anxiety that kind of

24 (0.4) $\mathrm{mh}(0.3)$ \#that kind of pressing feeling or

25 that kind of\#, 
$26 \mathrm{~T}: \quad \uparrow \# \mathrm{M}: \mathrm{h \# ,}$

$27 \quad(1.0)$

28 P: \#agonized feeling\#,

In lines 1-3 the therapist takes up the patient's description of her anxiety and other negative emotions. However, rather than focusing on the emotions as such, she refers to the patient's rational action of wondering about the reasons for them (the patient herself has not explicitly brought up the why-question though it can be heard as implicit in her complaints about unusual nervousness). The therapist's utterance invites the patient to distance herself from her experience and to scrutinize it. In her response (lines 4, 6-9), the patient does not take the position thus offered but rather describes what her experience is like. By focusing on just the quality of the experience and by using several extreme case formulations (all the time, terribly, constantly, awfully), the patient offers her utterance as an expression of a strong negative feeling and thus keeps to the frame of troubles-telling, However, in the next turn in lines 11-13, the therapist does not take up the position of an affiliative troubles recipient but proceeds with a question on the quality and quantity of the anxiety. The therapist's word choice does this mean, pro forma, refers to a problem of understanding the meaning of the patient's words, indicating that the patient's experience is something that the therapist does not know about (cf. Voutilainen et al. 2010). This preface, the contrastive but, the design as a polar question and the orientation to quantity in the question (as in more anxious or depressed) direct the patient away from the position of a troubles-teller, towards a kind of diagnostic examination of her affect. Again, despite the patient' pursue of affiliation, the therapist maintains her project of looking at the anxiety from a distanced, analytic perspective that she introduced in lines $1-3$.

The subsequent turns show how the participants further maintain their positions. To gloss these turns, after the patient's answer in line 14 the therapist asks a follow-up question (lines 16-17) that enhances an analytic rather than affiliating line of action with regard to the patient's experience. In the expansion of her response (lines 23-28), the patient returns to troubles-telling, thereby not taking up the reflective position offered for her by the therapist.

\section{Calling into Question the Patient's Emotional Experience}

A further type of the therapist's response to the patient's emotional experience, incorporating the therapist's investigative project in this session, involves not only scrutinizing the experience but also that the therapist calls into question some aspects of the patient's description of her experience.

The following extract 3 shows a case in point. The patient has indicated that she would prefer just to close the curtains and sleep and the therapist has asked whether this would really alleviate the patient's problem. The patient first answers with an ambiguous 'I don't know' (line 1), after which she engages in accounting for her preference to stay at home (lines 3-9). The therapist's turn in focus is her response to the patient's account.

The extract also illustrates a turning point in the session, where the misalignment between the patient and the therapist surfaces in the interaction. Following the turning point, the therapist leads the patient to overtly consider her relationship towards the therapist, and thus tone down the misalignment as well as to later re-engage in the therapeutic task of the session. 


\section{Extract 3}

1 P: well mh he .hh (.) \#I don't know\#

$2 \quad$ (1.5) ((patient shifts position))

3 P: \#mmh\# (4.5)I don't suppose it would (0.9) \#solve anything

4 or\#, \#I don't know ca:use at home it is just so\# .hh

5 £safe \#and\# (0.5)£\#good to be\#£ \#like that not\#

$6 \quad$ (2.0) \#mmm\# (0.7) \#not like\# (1.5) \#if you don't

7 have to go anywhere you are not nervous about

8 anything you don't feel sick\# (.) \#at least not

9 so often\# .hff (0.3) \#mmh\#,

10 (.)

$11 \mathrm{~T}$ : \#So you are saying that you feel at home for real then

12 if you drew the curtains you would feel \# .hhh $>$ good

13 for real there\# [hhh

$14 \mathrm{P}$ : $\quad$ [Well no::t necessarily if I have $<$ (.)

15 something $<$. hh (1.2) \#mmh well something like (0.5) \#if I

16 have free from work\# (0.7) \# you don't have to go

17 anywhere for a while so\# (0.3) then you might even feel

18 quite go- $\mathrm{g}(\mathrm{h})$ ood \#for a couple of days\# <like the

19 whole day $>$ that

The patient's account in lines 4-9 has an affective tone: the patient utters the expression 'safe and good to be' in a smiley, soft voice and that way can be heard to invite recognition of the experience she is talking about as well as acceptance of the account for her preference to stay home. The therapist keeps to her project (lines 11-13): instead of showing recognition of the patient's experience or acceptance of the account, she reformulates the patient's words in a way that calls into question the patient's account of her experience (conveying scepticism through phrase for real in lines 11 and 12) and thus strongly directs the patient to re-estimate it.

The therapist's turn has a paradoxical presupposition: the suggestion 'so you are saying that you feel at home for real' expects the patient to confirm the formulation but at the same time the scepticism works against that. The patient responds in line 14 by admitting that how she described her experience is not necessarily the case. However, in the rest of the utterance, she brings out a situation where staying home might actually feel good (lines 15-19). Her response is marked as dispreferred (deviating from the syntactic presupposition of the therapist's question) by the particle well (no in the original Finnish data) and the stretching of the negation word ' $n o:: t$ ' but it is delivered without delay (rather rapidly) (see Pomerantz 1984). This can be heard as an orientation to the irony or challenge incorporated in the therapist's paradoxical presupposition. So though the patient takes the action that the therapist made relevant (re-estimates her experience), through the timing of her turn and by bringing out a situation where her original idea is valid, she seems to orient to a frame of an argument and that way resist the therapist's project.

After what is shown in the extract, the therapist and the patient talk for a short while about the patient's experience, maintaining their positions: the therapist being sceptical and the patient resisting the therapist's project. Thereafter the therapist changes the subject by asking about the current state of the patient's relationship with her partner. This topical shift starts a course of interaction, during which the therapist manages to mitigate the misalignment between the patient and herself and continue her therapeutic project. 
In sum, with her responses to the patient's descriptions of her emotional experience in the beginning part of the session, the therapist suggested investigative orientation and refrained from affiliating with the patient's descriptions of negative emotion. In place of a response, the therapist took initiative, in the form of a question or a request for confirmation, inviting the patient to look at her experience from a distanced perspective and to re-evaluate it. She did this by focusing away from the emotional aspects of the patient's account, by scrutinizing the emotion, or by calling into question some aspects of it. The patient, on the other hand, consistently resisted the therapist's project and returned to describing her negative experience, thus keeping to the frame of troublestelling. The diverging projects of the participants lead to escalation of the misalignment (see Extract 3). We do not believe that this misalignment was where the therapist was aiming to, but nevertheless it becomes now a basis to the therapist's project in the rest of the session.

\section{Second Phase: Taking the Focus to Current Interaction}

In the second phase, the topic of the discussion changes to how the patient feels that other people, including the therapist, take the patient's decision to miss the job interview. In this discussion, the therapist focuses on the current relation between herself and the patient, and takes up the possibility that the patient may think that the therapist is disappointed with her. In this latter part of the session, the therapist's talk about the therapeutic relationship helps the participants to attend to and to mitigate the misalignment that arose in the first part of the session.

During this second phase, the discussion on the negative feelings between the participants (i.e. disappointment that the patient might attribute to the therapist) leads the therapist first to explicate her feelings towards the patient (i.e. to point out that she is not disappointed). Further on, the therapist suggests that the patient might project her own disappointment to others. This reflexive discussion leads the patient to further examine her feelings regarding her decision not to go to the job interview. This new discussion is characterized by a degree of alignment between the participants, and hence is different from the discussion in the first part. However, even in this second part, the therapist treats the participants' experiences as separate: she avoids taking a similar stance towards the patient's experience as the patient, unlike in conventional empathetic responses to troubles-tellings (cf. Ruusuvuori 2005, 2007; Peräkylä 2008; Voutilainen et al. 2010). The patient, in turn, still seeks to return to the position of troubles-teller.

A key exchange in which the participants address the interactional difficulties they had in the first part of the session is presented in extract 4 below. We show this extract to present how the misalignment is referred to in the latter part of the session. We do not analyze the extract in more detail since our focus is on how the therapist takes the focus to the therapeutic relationship before this point and how she further directs the patient to examine her experience using discussion about the therapeutic relationship as her resource. Before this extract, the therapist has suggested that the patient might feel that the therapist is disappointed by the patient, because the therapist has during the therapy intensively 'lived' with the patient. In her response, the patient admits that she does think the therapist could be disappointed. The therapist then links this attribution of disappointment to what happened between the participants earlier in this particular session: 


\section{Extract 4}

1 T: .hfff Yeah I just somehow began to think that e:rm::h hff

2 (5.7) .hff (.) \#mth so I began to think about just this

3 mm relationship between us and then that as I\# (.) as

$4 \quad$ I I myself had a kind of.hhh (.) \#fe- feeling

5 that you: do:n't\# that you would not have liked

6 to @£ta:lk about this who(h)le thing with me

$7 \quad$ [at all

8 P: [\#Yeah yeah well yes maybe it was so I did

9 not\# [(0.7) \#analyse it so\#,

$10 \mathrm{~T}: \quad[. \mathrm{hhh}$

11 P: why I don't wa:nt to but I had that kind of

12 \#feeling that I don't\#,

$13 \mathrm{~T}: \mathrm{Mm}$,

14 P: @want to@,

$15 \quad(1.5)$

16 T: Mm,

17 P: [\#M::h\#,

$18 \mathrm{~T}$ : [\#And I just\# (.) \#I did not think about it in the

19 first place either [I just\#,

$20 \mathrm{P}$ : $\quad[\mathrm{Mm}$,

$21 \mathrm{~T}$ : \#thought that it sounds like that\# .hh[hh

$22 \mathrm{P:}$ [\#£Mm£\# hff

$23 \mathrm{~T}$ : that yo:u are now somewhat £in a [resistant

$24 \mathrm{P}$ : $\quad[\mathrm{Mm}$,

$25 \mathrm{~T}$ : $\operatorname{mood}$ and£,

26 P: he he he he [he .hh

$27 \mathrm{~T}$ : [\#and you have sometimes been different and

$28 \mathrm{~mm} \#$ (.) \#or I have felt different [so\#,

29 P:

30

$[\mathrm{Mm}$,

$31 \mathrm{~T}$ : \#mth so could that then somehow link to

32 [that issue\#,

33 P: [Yeah I guess so,

Here the therapist explicates that there were difficulties in interaction between the participants during the earlier part of the session, formulates them as the patient's unwillingness to talk about the decision not to go to the interview, and finally (in lines 31-32) suggests that it is linked to the patient's belief that the therapist is disappointed by the patient's failure to go the interview (which is referred to as 'that issue' in line 31). The patient confirms the suggestion.

In what follows, we will track down the ways in which the therapist seeks to shift the focus of talk to the patient's perception of the therapist's disappointment, thereby gradually directs the patient to examine the workings of her own mind. This discussion is instigated by the therapist's question about the state of the patient's relationship with her partner. In response to this, the patient refers to her decision to miss the interview, wondering whether her partner is disappointed with her because of that. The therapist then directs the talk to the pressures that the patient feels are coming at her from other people. The extract 
below shows a point in the session where the therapist asks whether the patient feels such pressures also coming from her (the therapist).

\section{Extract 5}

1 T: Well do you feel that something might come from me

2 as well .hhh

3 P: $\uparrow \#$ Well I don't know\# (.) \#eee\# (0.6) maybe somehow

4 to some extent (2.4) like in such a way that $(0.7) £$

5 that you get disappointed too $£$ he he he [.hh

$6 \mathrm{~T}$ :

[\#M::h\#,

7 P: $\quad$.hh (0.9) \#Or $<$ or $<$ just that my coach (0.3) ee (.)gets

8 disappointed (.) I mean I said to her/him too\# I mean

9 s/he asked .hhh \#that did you get\# (2.0) [\#an::d\#,

$10 \mathrm{~T}$ : [\#mth\# (.) Did you get uninvited,

$11 \mathrm{P}:$ [Yeah,

$12 \mathrm{~T}: \quad[\mathrm{M}:: \mathrm{h}$,

13 (11.3)

14 T: \#Mth\# Well at least I can't sa:y about my own

15 feeling that it would be (.)@disappointment $@$,

16 P: M::h,

17 T: .hhh [I dont do- I don't erm feel \#like that so

19 P: $\quad$ [snff

20 T: tha::t I\#,\#would be now somehow disappointed\#,

$21 \quad(0.3)$

22 P: M::h,

23 T: .hhh hhh \#I'd have had an expectation like that\#

24 (0.9).hhh (2.3) .hh like it's ha:rd to make like

25 \#that kind of\# (1.4) .hhh (0.6) \#definition about it but

26 I mean I thought\#(0.4).snff \#mth\# that what you yourself

27 talked about it \#like it would have been a victory to you

28 yourself so then I can of course be sorry\#,

29 P: [\#M::h\#?

$31 \mathrm{~T}$ : [\#for you so that\#,

$30 \quad(0.3)$

31 P: Yeah,

32 T: \#mth\# So if you feel bad about it yourself

$33 \quad$ [.hhh

34 P: [Yeah,

$35 \mathrm{~T}$ : \#that you are not go:ing\#,

$36 \quad(0.5)$

37 P: Yea[h,

$38 \mathrm{~T}: \quad[. \mathrm{hhh}$

39 P: \#Well on the one hand I do and on the other

40 hand it is a relief to have decided not\# (0.9)

41 \#not to go now\#,

By taking up the possibility that the patient might feel that also the therapist is a source of pressures to her the therapist creates an opportunity for the patient to describe negative or conflicting aspects of their relationship. In lines 3-5, as an answer to the question, the 
patient admits that she feels, to some extent, that the therapist would be disappointed with her, and then in lines 7-9 she turns to talk about the same feeling about her coach. The therapist receives this in line 10 by completing the patient's turn, which can be seen to display understanding (Lerner 1991).

From line 14 on (after a long gap, 11.3 seconds in line 13), the therapist responds by describing her own current feeling: that it is not disappointment, and further, that she can feel sorry for the patient if the patient herself feels bad about her not going to the interview. Thus, the therapist responds to the patient's worry for disappointing people (including the therapist) in the context of the therapeutic relationship: she does not focus on the patient's experience but discloses that of her own. More importantly, the therapist's utterance is designed as one that reflects upon rather than expresses her emotion. The design of the therapist's turn, containing such contrastive expressions as I can't say and it's hard to define that way (lines 14, 24-25), takes distance to the affect that she is describing and so directs the interaction to a frame of reflection upon feelings rather than expression of them. On the other hand, the therapist seems to be talking about the relationship of the participants as she takes a position where her possible feelings of disappointment are described as existing only in relation to patient's own feelings of disappointment, not to anything the patient has actually done or said - in other words she claims that she recognizes the patient's possible feelings of disappointment of not going to the interview although she does not affiliate with her immediate descriptions of problematic feelings. Thus the therapist can be heard to slightly tone down the misalignment that was on the surface some minutes ago. However, the therapist's utterances clearly separate the patient's experiences from her own: she describes her own feelings and perceptions and does not indicate access to those of the patient's (see lines 26-28, 32), and for several times addresses the patient as you yourself (lines 26, 28, and 32).

In lines 39-41 the patient describes how she feels about her decision about the interview (which theme was made possible in the latter part of the therapist's utterance in lines 32 and 35). The therapist thus managed to invite the patient to elaborate her contradictory feelings about the job interview, which the patient has declined to do earlier in the session. At this point, the participants temporarily gain a new kind of alignment: they share a mutual frame of talk, that of reflective talk on emotion.

After the utterances shown in the extract, the patient moves to talk about her career plans in general, following which the therapist "retopicalizes" the pressure that the patient feels that is laid upon her by other people's expectations. In this context the patient starts to talk about her mother's possible reaction to her not going to the interview, moving again towards what can be heard as troubles-telling. Next example shows the ending of this utterance. Following the patient's turn, the therapist takes the talk again back to their mutual relationship and the possible disappointment of the therapist (that may be attributed to her by the patient).

\section{Extract 6}

1 \#Yeah but on the other hand she surely then

2 gets disappointed because she has thought that\#.hhh that

3 I have like \#got\# (.) \#better\#

4 and\# (1.2) \#like\# (.)\#been able to work and

5 .hff (1.2) \#mh\#,

$6 \quad(3.0)$

7 T: .hh I began to think (.) as you talked about that erm if 
8 \#mother then is only worried and sad and sorry and\# [.hhh

$9 \mathrm{P:}$ $[\mathrm{Mh}$,

$10 \mathrm{~T}$ : \#I thought that in fact I said just a moment

11 ago that I would feel like that .hhh how seriously you

12 really think that I'd be disappointed that

13 I have figured that you have got [better and\#, $14 \mathrm{P}$ :

15 [hff (0.4) .hh Yeah,

16 P: Mh,

$17 \mathrm{~T}$ : So that somehow I began to think that mother

18 could yet be the one to understand but am I:

19 \#then somehow the one who\#,

20 P: £Well [no no£,

$21 \mathrm{~T}: \quad[£ . h h$ he he [.hh£

$22 \mathrm{P:}$

[£he no he no (.) \#I mean just

23

that\#£ (0.9) \#not maybe it is mos- mostly it is

24 ee mo::ther whose\# .hhh \#whose like\# (1.5)

In lines $1-5$, the patient elaborates her worry about disappointing her mother. She finishes by pondering that mother surely will get disappointed, because she has thought that the patient has got better. The patient gives this in contrast to what she has said earlier about how mother might understand how anxious she has been and so also understand her decision to miss the interview.

In her consequent turn at talk from line 7 onwards, the therapist does not take up the issue of the mother's possible disappointment but instead shifts the focus, as she did in the previous extract, to the disappointment she suggests the patient attributes to her (the therapist). The therapist presents her statement about this attribution as one that arises from the current interaction: she started to feel that the patient might think that she is disappointed while the patient spoke about her mother (lines 7-8, 17). Instead of responding to the patient's worry concerning a third party (her mother), the therapist focuses on the negative emotion that is currently possibly present in the therapeutic relationship. The therapist uses such reflexive expressions as I began to think (lines 7 and 17) and I thought (line 10) and thus indicates that she talks about her own perception of the patient's words. This can be seen as taking again reflective distance to the emotion in the current interaction and pointing to separateness of experiences of the participants.

The patient receives the therapist's turn with a strong denial (double no in line 20) and after that there is a spell of mutual laughter in lines 21-22. This is the first mutual laughter in this session, and it has a sense of releasing some of the tensions of the interaction so far. The patient's immediate response, however, is one that avoids taking up the reflective and interpretive perspective about the therapeutic relationship that the therapist's utterance involved: the patient merely denies that she would think that the therapist would be disappointed or would not understand her decision (see lines 17-20). Through her laughter, the patient again produces two 'no's (line 22), thereafter elaborating the reasons why she is concerned about the mother, and not the therapist, being disappointed at her.

Following the excerpt, the patient moves back to express her worry about her mother, while the therapist in turn takes the focus back to the therapeutic relationship by pursuing her previous suggestion about the patient feeling that the therapist might be disappointed. This time the participants temporarily reach an alignment, as the patient in her response takes up this interpretive and reflective frame and starts to reflect on the possibility that she does feel the therapist is disappointed at her. 
This reflection continues in the consequent discussion, where the therapist and the patient talk about the problems in the interaction earlier in the session shown above in Extract 4. After this point the talk moves to how the patient feels that other people (including the therapist) may not understand the nature of her experience. The patient also discloses that the therapist said something in the previous session that she perceived as not understanding her anxiety. In her responses the therapist now affiliates with the patient but also keeps to her project: to pointing at the patient's own contradictive feelings about her decision and their relation to how she thinks about other people's reactions. Below we show the ending of this phase of the discussion.

\section{Extract 7}

1 mmm like some people think that(h) (1.8)

2 \#ooh mmmh\# (.) \#loser- losers give in\# (.)so that\#

3 .hhh \#so that as it still is not like that\#,

$4 \quad(2.0)$

5 T: M::h,

$6 \quad(3.0)$

7 P: .hh

8 (8.0)

9 T: M::h \#mth\# it is a terribly contradictory thing

10 indeed (.) [.hhh

$11 \mathrm{P}$ : [Yeah.

$12 \mathrm{~T}$ : \#to give up something [that you don't really

$13 \mathrm{P}: \quad$ [\#Mm\#,

$14 \mathrm{~T}$ : you think over somewhat\#,

$15 \mathrm{~T}$ : \#and then although\# .hhh hhh erm \#you're too scared

16 and\#,

17 P: [Yeah,

$18 \mathrm{~T}$ : [\#then you start to thi:nk\# @ like could I have made

19 it anyway and@,

$20 \mathrm{P}$ : [Yeah yeah,

$21 \mathrm{~T}: \quad[M m$ mm m::h,

$22 \quad(0.3)$

23 T: \#mth\# I do have some experience about that .hhh

$24 \mathrm{~T}: \quad$ [hfff

25 P: $\quad$ hfff

$26 \quad(3.2)$

27 P: \#M::h\# (0.3) \#but I mean-\# (3.4)\#m::h\#,

In lines $1-3$, through phrasing what some people wrongly think, the patient implies that the therapist (among others) has not totally grasped the patient's point of view, which is that she has not given in too easily and that her decision to not to go to the job interview involves struggling. Starting from line 9, the therapist assesses that what the patient is talking about is a contradictory thing, defines what that thing contains and after this definition states that she does have some experience of that (line 23). In her response the therapist gives details of the issue the patient has complained about (lines 12, 14-16, 18-19) and in this way displays affiliation and conveys to the patient that she really does understand the difficulty that the patient is experiencing (see Ruusuvuori 2005). On the other hand, instead of straightforwardly agreeing with the patient's claim that it is not that losers give in, the therapist formulates the issue from a different perspective, pointing at the patient's struggling. She 
also finishes with a claim that explicitly concerns her own experience (line 23) and so responds to the patient's implicit claim about not understanding. Thus, the therapist keeps from thoroughly accepting the affiliating position of a troubles-recipient that the patient again offers her, and directs the talk towards reflecting the patient's inner process, and the therapeutic relationship (where the experiences of the participant's are separate).

After what is shown in the extract, the patient moves to talk about job interviews in general and thus does not take up the therapist's offer to reflect upon her own experience. The talk about the patient's decision and the therapeutic relationship ended to these positions: the therapist suggested that the expectations, disappointment and blame about giving in too easily that the patient feels are addressed to her by other people (including the therapist) are an inner phenomenon of the patient's self; and the patient resisted this line of thought by taking the talk elsewhere. (Until the end of the session the talk is about means of managing nervousness. The difficulties between the participants in this session were discussed also in the next session.)

We have now achieved an overall view of the participants' projects in this particular session. The first part of the session can be characterized as prolonged and cumulating misalignment: the therapist declined the position of an affiliating troubles recipient that the patient offered her and instead focused away from the patient's emotion, scrutinized it, or even called it into question. During the second part of the session, the therapist's project was modified. She actively worked towards solving the misalignment by focusing on the relationship between the participants. More of an alignment between the participants ensued. The therapist sought to show to the patient that she attributes to the therapist the disappointment at herself, but also showed understanding of the patient's experience. More importantly, however, this was done in a reflective, interpretive frame. The therapist worked to help the patient to reflect upon her own feelings and ways of relating to other people. Even though the patient recurrently moved back to her initial position as a troublesteller, during this second phase there were several moments where she got engaged in more reflective contemplation of her feelings.

Even though the therapist's project changed during the course of this session, something in it remained the same. The therapist's way of maintaining the separateness of the patient's, the therapist's, and other people's experiences seems to be a connecting string between the two phases of the session. In the first phase, the therapist systematically avoided taking a position where she, in a complementary way, would affiliate with the patient's experience. Thereby, she avoided sharing the perspectives that the patient was inviting her to. During the second phase, the therapist disclosed her own feelings and showed that they were different from what the patient possibly expected them to be. She topicalized the therapeutic relationship and thereby both managed to alleviate the misalignment and to evoke a somewhat more reflective frame in discussing the patient's experience.

\section{Conclusion}

According to Peräkylä (2008), there are constant matches and mismatches between the actions (and the projects that they embody) of the therapist and client in psychotherapy interaction - complementarity is mingled with noncomplementarity. Therapy work consists of constantly dealing with these mismatches in order to achieve the current therapeutic task. In this article we have seen a case where the therapist skillfully a) tales up the therapeutic relation as a topic of talk in dealing with such a mismatch and b) resists the position that the patient offers in helping her to reflect upon her tendencies to react.

Conversation analysis provides a method to describe in detail what sort of practices of talk are used to reach therapeutic goals in psychotherapy sessions. Stiles (2008) has 
suggested that by describing the actual course of conversation, CA analysis provides distinctions that elaborate the abstractions of therapy theories. Following this line of thought, the conversation analytical results of this article contribute to the clinical discussion on 'ruptures in therapeutic alliance' (e.g., Safran, Muran, Samstag \& Stevens 2001). At the beginning of the article, we cited Safran et al. (2001) who emphasize the importance of the ways in which the therapists recognize and address ruptures in the therapeutic alliance. Although we are not able to argue anything about the outcomes in terms of the entire therapeutic process of discussing such a rupture here, we have shown what sort of combinations of turns of talk amount to a rupture and how it can be managed.

In the particular session we have been investigating, the rupture emerged when the therapist avoided taking the position of an affiliating troubles recipient upon the patient's invitation. We can suggest that this avoidance was in line with the therapeutic task of the session. The patient's project of maintaining the positions of herself as the troubles-teller and the therapist as a troubles-recipient may (retrospectively) be seen as involving implicit attribution of disappointment to the therapist: through inviting the therapist to affiliate with her plight the patient invited her also to accept the decision that she offered as a part of the plight (see Extract 1). Instead of giving a complementary response to the patient's position, the therapist sought to take it under investigation (see Safran \& Segal 1990).

The way in which the therapist chose to solve the misalignment also connects to the literature of cognitive-constructivist therapy. Safran et al. (2001) suggest that therapists may have considerable difficulty in recognizing moments where the therapeutic alliance is ruptured, and that it is difficult to address such problems in the course of treatment. The session described in this article shows a case where the therapist not only recognizes the problem but also topicalizes the therapeutic relation in order to deal with the problem. Instead of rigidly keeping to her line of action in the first phase of the session (of challenging patient's cognitions), she engages in exploring the state of their alliance and helps the patient to state her possible negative feeling about their relationship. Moreover, throughout the session the therapist keeps to position in which hers and the patient's perspectives are separate, and it seems that in this way she to some extent manages to 'demonstrate' to the patient relations between her (patient's) own emotions and how she attributes emotions to others.

This article not only provides empirical support for the claims that affective misalignment in the therapeutic relationship and its management are a (normal, maybe a significant) part of a therapeutic process (Safran \& Segal 1990). It also shows in detail how this kind of misalignment can emerge and be dealt with, and how in the course of mending the rupture the therapeutic task may be kept along.

\section{References}

Antaki, C 2008, 'Formulations in psychotherapy', in A Peräkylä, C Antaki, S Vehviläinen \& I Leudar (eds.), Conversation analysis and psychotherapy, pp. 42-62, Cambridge University Press, Cambridge, UK.

Antaki, C, Barnes, R \& Leudar, I 2005, 'Diagnostic formulations in psychotherapy', Discourse Studies, vol. 7, pp. 627-47.

Arminen, I 2005, Institutional interaction, Ashgate, Aldershot, UK.

Beck, AT 1976. Cognitive therapy and the emotional disorders, International Universities Press, New York.

Buttny, D 1996, 'Client's and therapists' joint construction of the client's problems', Research on Language and Social Interaction, vol. 29, pp. 125-53.

Davis, K 1986, 'The process of problem (re)formulation in psychotherapy', Sociology of Health and Illness, vol. 8, pp. 44-74. 
Drew, P \& Heritage, J 1992, 'Analyzing talk at work: an introduction', in P Drew \& J Heritage (eds.), Talk at work: interaction in institutional settings, pp. 3-65, Cambridge University Press, Cambridge, UK.

Edwards, D 2000, 'Extreme case formulations: softeners, investment, and doing nonliteral', Research on Language and Social Interaction, vol. 33, pp. 347-73.

Greenberg, L \& Safran, J 1987, Emotion in psychotherapy: affect, cognition and the process of change, Guilford Press, New York.

Guidano, V 1991, The self in process, Guilford Press, New York.

Horvath, AO \& Symonds, BD 1991, 'Relation between working alliance and outcome in psychotherapy: a meta-analysis', Journal of Consulting and Clinical Psychology, vol. 38, pp. 139-49.

Hutchby, I 2005, “'Active listening": Formulations and the elicitation of feeling-talk in child councelling', Research on Language and Social Interaction, vol. 38, pp. 303-29.

Jefferson, G 1988, 'On the sequential organization of troubles-talk in ordinary conversation', Social Problems, vol. 35, pp. 418-41.

Jefferson, G \& Lee, J 1992, 'The rejection of advise: managing the problematic convergence of a "troubles-telling" and a "service encounter", in P Drew \& J Heritage (eds.), Talk at work, pp. 521-71, Cambridge University Press, Cambridge, UK.

Lerner, GH 1991, 'On the syntax of sentences in progress', Language in Society, vol. 20, pp. 441-58.

Martin, DJ, Garske, JP \& Davis, MK 2000, 'Relation of the therapeutic alliance with outcome and other variables: a meta-analytic review', Journal of Counseling and Clinical Psychology, vol. 68, pp. $438-50$.

Peräkylä, A 2004, 'Making links in psychoanalytic interpretations: a conversation analytic view', Psychotherapy Research, vol. 14, pp. 289-307.

Peräkylä, A 2008, 'Conversation analysis and psychoanalysis: interpretation, affect and intersubjectivity', in A Peräkylä, C Antaki, S Vehviläinen \& I Leudar (eds.), Conversation analysis and psychotherapy, pp. 100-19, Cambridge University Press, Cambridge, UK.

Peräkylä, A, Antaki, C, Vehviläinen, S \& Leudar, I 2008, 'Analyzing psychotherapy in practice', in A Peräkylä, C Antaki, S Vehviläinen \& I Leudar (eds.), Conversation analysis and psychotherapy, pp. 5-25, Cambridge University Press, Cambridge, UK.

Pomerantz, A 1984, 'Agreeing and disagreeing with assessments: some features of preferred/dispreferred turn-shapes', in JM Atkinson \& J Heritage (eds.), Structures of social action, pp. 57-101, Cambridge University Press, Cambridge, UK.

Ruusuvuori, J 2005, "Empathy" and "sympathy" in action: attending to patients' troubles in Finnish homeopathic and general practice consultations', Social Psychology Quarterly, vol. 68, pp. 204-22.

Ruusuvuori, J 2007, 'Managing affect. Integration of empathy and problem solving in health care encounters', Discourse Studies, vol. 9, pp. 597-622.

Ruusuvuori, J \& Voutilainen, L 2009, 'Comparing interaction in different types of health care encounter', in M Haakana, M Laakso \& J Lindström (eds.), Talk in interaction. Comparative dimensions, pp. 206-30, Finnish Literature Society, Studia Fennica Linguistica, Helsinki, Finland.

Safran, JD \& Muran, JC 2006, 'Has the concept of the alliance outlived its usefulness?' Psychotherapy, vol. 43, pp. 286-91.

Safran, JD, Muran, JC, Wallner Samstag, L \& Stevens, C 2001, 'Repairing therapeutic alliance ruptures', Psychotherapy, vol. 38, pp. 406-12.

Safran, JD \& Segal, ZV 1990, Interpersonal process in cognitive therapy, Basic Books, New York.

Schegloff, E 2006, Sequence organization in interaction: a primer in conversation analysis, Cambridge University Press, Cambridge, UK.

Stiles, WB 2008, 'Foreword: filling the gaps', in A Peräkylä, C Antaki, S Vehviläinen \& I Leudar (eds.), Conversation analysis and psychotherapy, pp. 1-4, Cambridge University Press, Cambridge, UK.

Toskala, A \& Hartikainen, K 2005, Minuuden rakentuminen. Psyykkinen kehitys ja kognitiiviskonstruktiivinen psykoterapia [Construction of the self. Mental development and cognitiveconstructivist psychotherapy], Jyväskylän koulutuskeskus, Jyväskylä, Finland. 
Vehviläinen, S 2003, 'Preparing and delivering interpretations in psychoanalytic interaction', Text, vol. 23, pp. 573-606.

Voutilainen, L, Peräkylä, A \& Ruusuvuori, J 2010, 'Recognition and interpretation: responding to emotional experience in psychotherapy', Research on Language and Social Interaction, vol. 43, pp. 85-107.

\section{About the Authors}

Liisa Voutilainen is post doctoral researcher in Sociology at the University of Helsinki. Her research topics include psychotherapeutic interaction, therapeutic change, and emotion and empathy in interaction. Her doctoral dissertation (2010) was a conversation analytical study on cognitive-constructivist psychotherapy.

Anssi Peräkylä is professor of Sociology at the University of Helsinki. His research topics include psychotherapy, medical interaction, and emotion in social interaction. He is the co-editor of Conversation Analysis and Psychotherapy (Cambridge University Press 2008).

Johanna Ruusuvuori is senior researcher in the Finnish Institute of Occupational Health. Her research topics include interaction between professionals and clients in health and social care, patient participation, emotion (e.g. empathy) in interaction, methods and evaluation of health promotion in working life. She has published two textbooks on qualitative research methods and has expertise in conversation analysis.

\section{Appendix}

\section{Transcription symbols:}

T: $\quad$ Speaker identification: therapist $(\mathrm{T})$, patient $(\mathrm{P})$

[ ] Brackets: onset and offset of overlapping talk

$=\quad$ Equals sign: no gap between two utterances

(0.0) Timed pause: silence measured in seconds and tenths of seconds

(.) A pause of less than 0.2 second

. Period: falling or terminal intonation

, Comma: level intonation

? Question mark: rising intonation

? $\quad$ Rise in pitch

? $\quad$ Fall in pitch

- $\quad$ A dash at the end of a word: an abrupt cutoff

$<\quad$ The talk immediately following is 'jump started': that is it begins with a rush.

$><$ Faster-paced talk than the surrounding talk

$<\quad$ Slower-paced talk than the surrounding talk

Underlining: some form of stress, audible in pitch or amplitude

Colon(s): prolongation of the immediately preceding sound

- Degree signs surrounding a passage of talk: talk at a lower volume than the surrounding talk

.hh A row of hs preceded by a dot: an inbreath

hh A row of hs without a dot: an outbreath

\#\# Number signs surrounding a passage of talk: spoken in a 'creaky' voice (vocal fry)

$£ \quad$ Smiley voice

@ Animated voice 